\title{
Sociometry in democracy
}

\author{
Børge Kristoffersen
}

Published online: 1 December 2017

(C) The Author(s) 2017. This article is an open access publication.

\begin{abstract}
This article has as its starting point on an early sociometric practice which was based on ideas of democracy and a theatrical cultural practice in the United States in the 1930s. By combining a re-reading of the sources on this early instance of sociometry with an interview with a practitioner of applied sociometry, the author makes an analysis of how sociometric applications are relevant in democratic practice today. In the analysis, a distinction is made between "cold" and "living" sociometry. Through references to different forms of play, and the improvisation theatre 'Das Stegreiftheater', the author shows the relationship between sociometry and drama and theatre and to the application of theatricality in democratic practice.
\end{abstract}

Keywords Sociometry · Democracy · New York State Training School for Girls • "living" sociometry · Das Stegreiftheater

\section{Soziometrie in der Demokratie}

Zusammenfassung Dieser Artikel hat als Ausgangspunkt eine frühe soziometrische Praxis, die auf Ideen der Demokratie und einer theatralischen Kulturpraxis in den Vereinigten Staaten in den 1930er-Jahren basierte. Durch die Kombination einer Neuauslesung der Quellen zu dieser Frühzeit der Soziometrie mit einem Interview mit einer Praktikerin der angewandten Soziometrie, macht der Autor eine Analyse, wie soziometrische Anwendungen in der demokratischen Praxis heute relevant sind. In der Analyse wird zwischen ,kalter“ und „lebendiger“ Soziometrie unterschieden. Durch Verweise auf verschiedene Spielformen und das Improvisationstheater „Das

This article is translated by Albert Collett and Børge Kristoffersen.

B. Kristoffersen $(\triangle)$

Elvegata 18, 7012 Trondheim, Norway

E-Mail: bkr@dmmh.no 
Stegreiftheater" zeigt der Autor die Beziehung zwischen Soziometrie und Drama und Theater sowie die Anwendung der Theatralität in der demokratischen Praxis.

Schlüsselwörter Soziometrie · Demokratie · New York State Training School für Mädchen · „lebendige“ Soziometrie, Das Stegreiftheater

\section{Introduction}

The ambition of this article is to contribute to a revitalization of sociometry's potential as democratic idea and theatre practice. With the quote "Sociometry can well be considered the cornerstone of a still underdeveloped science of democracy" (J. L. Moreno 1953, p. 113) as point of departure I will draw a line from 1934 till today. By going through literature linked to the original ideological foundation of sociometry and an interview with a practitioner of applied sociometry, Monica Zuretti, I will investigate sociometry's potential for practice today. Furthermore, I will promote sociometry in relation to democracy. Finally, by analysing the interview, I will describe forms of applied sociometry in the professional practice of the theatre. First to a possible starting point: 1934 .

\section{Early spread}

In 1934, J. L. Moreno published the book Who Shall Survive? The book is a major work in sociometry. It describes the organization of groups and the positions individuals have and take in groups (J. L. Moreno 1953, p. 51). In the book, sociometry is presented as a study that measures relations between people. At the same time it describes how sociometric studies are followed up by transformative actions through varying use of the theatre tool ${ }^{1}$. Through focus on the organization and potential of groups, the book tries, as the title reflects, to answer an evolutionary question from a humanist standpoint (Rasmussen and Kristoffersen 2011, p. 160). The empirical material of the book is taken from the teaching of girls at a specialized school in Hudson, USA, and is dedicated to Fannie French Morse (manager of the school) as a "Educator and Liberator of Youth" (J. L. Moreno 1934).

As democratic idea and practice, sociometry grows as professional discipline in American research and societal life in the 30s, 40s, 50s and 60s. Along with Who Shall Survive? the journal Sociometry Review, published from 1936 and from 1937 with the name Sociometry, was central to this growth. The journal is a channel of publication for notable contributors in American society and research of the era ${ }^{2}$.

\footnotetext{
1 Theatre tool is here the use of participating, exploring and creative theatre forms applied on everyday arenas, an understanding of theatre beyond theatre as plain impartation of art. Here its called "Das Stegreiftheater" (Rasmussen and Kristoffersen 2014, p. 41).

2 Names like Gordon W. Allport, Jerome S. Bruner, Kurt Lewin, Margaret Mead and John Dewey, (J. D. Moreno 2014, p. 143, p. 165, and J. Fox 1987, p. vii).
} 
1934 is also the year when sociometry becomes part of President Franklin D. Roosevelt's big democratization project New Deal. The trigger is the mind-set in Who Shall Survive? Roosevelt had read it and as part of the reform program New Deal the book gives inspiration to the strife to re-establish democracy after the depression in the USA in the 1920s and 30s. In a conversation with Moreno, Roosevelt said about Who Shall Survive? "This looks like progressive sociology', he said, and added pensively, 'if I had not taken my present course this is what I would like to do.' He further stated, 'When I am back in Washington I will see where your ideas can be put to use", (J. D. Moreno 2014, p. 134).

In the following years, the American administration initiated several democratization projects based on the mind-set in the book. One of these is "Centerville", administrated by "US Department of Agriculture Resettlement Administration" (Ibid.). The idea of sociometry as a democratic social science continued to grow in the decades of the depression and/.../ "reaching the height of its appeal as a scientific examination of democracy in the 1930s" (Op.cit., p. 135).

A significant shift in the spread, focus and use of sociometry can be traced to 1954. At the time, the magazine Sociometry was donated to American Sociological Association (Op.cit., p. 254). Through the donation, sociometry is gradually shifted to sociological research and in this way its ideas and mind-set is turned towards a purely sociological research method where especially the sociogram (a social graph that visualizes the relations in a group) becomes a widely used diagnostic tool of analysis. With the transfer, a rupture occurs with sociometry's original idea and use. ${ }^{3}$ Not the least downplayed is sociometry's use of the theatre tool. In the early sociometry, the theatre tool is fundamental in the overstepping and reestablishment of positions in groups. With the transfer to sociology, a "cold sociometry" comes into being (Op.cit., p. 130) where aesthetic actions through theatre productions and spontaneity training disappear. A core concern in this development is that in the loss of a theatre practice also lies a loss of a democratic view on culture and with that probably also the realization of sociometry's full potential (Rasmussen and Kristoffersen 2011, p. 34).

\section{Sociometry as democratic idea and cultural practice}

Sociometry as democratic idea and cultural practice was originally developed in contact with marginalized groups and institutions in society. In work with displaced persons (Mitterndorf, near Vienna 1917), in work with actors ("Das Stegreiftheater", Vienna 1921), with prison inmates (Sing Sing, USA 1932) and in work at a special school for girls (New York State Training School for Girls 1932-34) sociometry springs up as practice (R. F. Marineau 1989, p. 111). In the encounter with an American research environment in the 1930s and 40s where Dewey in particular is a central professional meeting point (J. D. Moreno 2014, p. 165), sociometry as democratic idea and cultural practice is further developed.

\footnotetext{
3 Op. cit., p. 135; Løkken and Søbstad (2013); Sletta (1983); Hellevik (1977).
} 
The understanding of democracy that arises in the early practice phase of sociometry is not about right to vote democracy or representative democracy. The understanding of democracy in question deals with democracy as more than a form of rule: "A democracy is more than a form of government; it is primarily a mode of associate living, of conjoint communicated living" (J. Dewey [1916] 1961, p. 87). In the same way as Dewey's idea of democracy, democracy in sociometry is a life form that has to do with commitment, sharing common experiences that affect, about inclusion, about participation in a common society. The ideal of democracy is that society must be built on everybody's right and duty to participate. Woven into such an understanding of democracy it appears that the foundation of sociometry springs up through contact with marginalized groups. A core thought is that it must be possible to measure a functioning democracy in relation to how it deals with those who are marginalized. May be this is the meaning of democracy as a "still underdeveloped science" (J. L. Moreno 1953, p. 113). Democracy is a process, a continuous unending practice that has to be recreated.

To the understanding of how the relationship between sociometry and democracy interact also belongs a view on knowledge and culture-a pragmatic view on knowledge and culture. It touches on the relationship between participant and spectator, between subject and object. A pragmatic view on knowledge and culture criticizes the division between worlds in the form of dualisms. In such a view, participation is seen as a prerequisite for a living democracy. Participation also constitutes the foundation for the development of knowledge and intellect. Pragmatism reacts to a rational as well as empirical view on culture and knowledge where the individual is seen as a spectator of the world, where the subject, "the knower", and the object, "the thing to be known", live in separate worlds. According to Dewey, this separation leads to dualisms we encounter in a number of areas: between subjective and objective knowledge, between body and mind, between theory and practice, intellect and feelings, and between values and facts (J. Dewey [1916] 1961, p. 293). In sociometry, this dualism is mirrored in the relationship between the original sociometry and a "cold sociometry".

In the early practice phase of sociometry, a pragmatic view on knowledge and culture can be traced. In particular we see it in relation to the intersubjective. The intersubjective is the first one encounters in sociometry, in the shape of the individual's choice. The individual chooses; it adds and subtracts choices; it is drawn towards and rejects. The choices may be positive and negative, ambivalent and neutral in the encounter with others. Encounters and contacts between people contribute to establishing networks, to the formation of "stars" and "isolated" in groups and societies. Patterns and structures in human interaction in forms of adding and subtracting choices create prerequisites not only for sociality but also for self-formation. ${ }^{4}$ The patterns are there and often they are invisible to the human eye. This is what the first sociograms open the eye to. They make social patterns visible. From early on, sociometry is therefore described as a social microscope (J. L. Moreno 1953, p. 283).

\footnotetext{
4 George Herbert Mead's role theory about self-formation is a central source of inspiration for sociometry (Moreno 1953, p. 15).
} 
In the encounter with "incorrigible" girls (official description in the 1930s) at New York State Training School for Girls, sociometry is used to understand how relations, ties and bonding in groups arise and develop. It investigates how ties influence elements concerning life and interaction in general as well as learning and formation of knowledge in particular. The first sociometric studies showed that individuals' bonding in groups was not so much about personality but rather about acceptance of dissimilarities and mutual respect. And not only that! Through the use of theatrical tools, sociometry is just as much, or rather, a tool used to create new reality, to transform ${ }^{5}$ less fortunate qualities in social interaction. In a participating sociometry, the "incorrigible" girls may experience and learn more adequate actions, actions that can give new feelings of coping in social interaction-all the while based on the idea of democratic participation (Z. Moreno 2012, p. 514).

Again we find merging with Dewey's idea about democracy:

The democracy which proclaims equality of opportunity as its ideal requires an education in which learning and social application, ideas and practice, work and recognition of the meaning of what is done, are united from the beginning and for all (Dewey and Dewey [1915] 2008, p. 180).

\section{Democracy in group formation, an example}

"Incorrigible" is the official name of those that constitute the main research material in Who Shall Survive? They are young criminal and convicted girls from New York State Training School for Girls, a governmental special school for girls between the ages of twelve and sixteen. In 1932, more than 400 girls live at the school. The girls are accommodated in cottages, sixteen in all.

In the chapter "Authoritative and Democratic Methods of Grouping" (J. L. Moreno 1953, pp. 652-673), we learn that 28 girls live together in one of these cottages. In the dining room where the girls have their meals, there are seven tables. At mealtime the girls gather around the tables at random. The arrangement leads eight girls to the table where the girl with highest attraction is seated. Since the table only accommodates four, there is a fight for the position next to the preferred girl. Clashes and selfish actions become part of the "warm-up" to the meals. If one of the not preferred girls sits down at another table, she risks being seated with someone she doesn't like. The technique of allowing the girls to place themselves randomly around the tables reveals problems that call for authoritative actions from adults, and against the will of most of the girls. Another technique is to let the housemother exercise her authority by placing the girls at the tables at mealtime. At the same time there is the risk that the girls' dissatisfaction and inherent protests against the adults and the world around them grows.

Another procedure is to ask the girls who they want to be seated next to, and since each table has four seats, one may choose three. In the criteria for the choice

\footnotetext{
5 The same year Moreno publishes Who Shall Survive? Dewey releases his main opus on aesthetics and art, "Art as Experience" (1934). Here they share the same mind-sets based on transformation of experience.
} 
lie a mutual contract that everything will be done so that everyone gets at least one of her choices fulfilled, if not the first choice, so the second, and if that isn't possible, the third. When everyone gets to choose, there has to be reciprocity in the premises. The optimal seating occurs when as many as possible have their mutual choices satisfied.

The order is as follows: a subject's first choice is reciprocated by a first choice. $1: 1$, a subject's first choice is reciprocated by a second choice, $1: 2$, a subject's first choice is reciprocated by a third choice, $1: 3$, a subject' second choice is reciprocated by a first choice, $2: 1$; and so forth, $2: 2 ; 2: 3 ; 3: 1 ; 3: 2 ; 3: 3$. Where there is no choice that meets with a mutual response, the first choice of the girl (1:0) becomes her optimum, that is, from her point of view, the best placement for her available within the structure. These simple rules guide each placement (Op.cit., p. 653).

The implementation of the sociometric procedure sketched here has an impact on multiple levels: (1) The choice of the girls is respected, (2) it helps the girls understand how they can avoid choosing blind alliances (choices that go in only one direction), (3) the isolated girls obtain contact with the girls they want to be with, girls they would otherwise not have become acquainted with, (4) more harmonious groups arise in the cottage and (5) the situation around the table improves at mealtimes. The procedure and experience linked to respect for their own choices give the girls a possible knowledge that makes it realistic for them to act more adequately later in life. All in all, an adequate piece of knowledge for a marginalized group of "incorrigible" girls. The sociometric studies also lead the girl with most choices, "key girls", to accompany the housemother when new girls arrive at the cottage. In this way, the recently arrived get accepted more speedily by the other girls.

For the school as a learning culture, the sociometric practice reveals that contact between recently arrived girls and "key girls" affects the acceptance of the recently arrived in the group as a whole. This prevents social isolation at an early stage. They discover that random placing at the tables fosters social blocking, which in turn contributes to the establishment of isolated persons. In addition it contributes to, at an institutional level, a knowledge that it is more helpful to respect the choices of the girls than to overrule them through the authoritarian actions of the adults, for instance by the housemother's interference in the seating at mealtimes (Op cit., p. 670).

The example above illustrates how a sociometric piece of work makes it possible to read a socially complex reality and at the same time contribute to a democratic practice. But to read or interpret and analyse this reality demands a spectator's view and the sociometric work doesn't stop at that. The spectator's view alone in sociometric investigations contribute, as we have seen, to the concept "cold sociometry". Sociometry without the theatre tool is rejected in in the early sociometry (J. D. Moreno 2014, p. 130). In the first practice, the material in the sociometric studies provides a guiding line in to the theatre tool. 


\section{Sociometry as clue to the theatre tool}

The first sociometry was developed during theatre productions with actors in "Das Stegreiftheater" (J. L. Moreno [1947] 1983), a spontaneity theatre in Vienna in the 1920s. In the development of sociometry as democratic practice in the 1930s, the techniques from "Das Stegreiftheater" were continued (J. L. Moreno 1953, p. 535). For the girls at New York State Training Schools for Girls, spontaneity theatre and role training became part of their learning program. It is used to create diversity in role repertoires where earlier and rigid roles no longer serve the purpose. " $/ . . . /$ in want of a manifold of living roles we can resort to fictitious roles which are brought as close as possible to the living ones. To accomplish this aim we have developed techniques for "training social spontaneity", (Op cit., p. 531). It is argued in favour of a pragmatic, aesthetic view on culture:

The objectives of our system of education in the past have been to train man for a series of rigid social situations and for a series of rigid vocations/.../ man is resourceful enough to become more highly differentiated and more flexible/..../ (Op cit., p. 533).

Stegreiftheater related to sociometry proves valuable in several ways. In the fictitious room, earlier "frozen" experiences in life are acted out: "things which one girl would not tell another or the housemother in life, she may act out in a play and the humour of it may prevent and heal many potential grievances which might otherwise have led to actual conflict." (Op cit., p. 534). The practice not only contributes to a change of frozen roles but also to a new experience of self. Through various theatre productions the girls can experience themselves as resourceful and versatile. New situations of cooperation arise; a productive climate of collaboration which the girls can profit from in other situations, in other arenas, in and out of school (Ibid.). As part of the democratic ideal for this practice, a film is made in 1933: "Spontaneity Training and Role Re-Training" (Marineau and Moreau 2003). The film shows how Stegreiftheater is used in the sociometric work at New York State Training School for Girls. One of the aims of the film is for the girls themselves to see it, comment on it and discuss it, and through that learn more about themselves and others.

In Who Shall Survive? theatre practice is described as a natural and fundamental part of sociometry. Stegreiftheater is used to create new reality; to transform rigid roles and frozen situations. And not the least: the understanding of theatre work is linked to a view on experience; the individual's subjective experiences and perceptions (J. L. Moreno 1953, p. 78).

It is this understanding that disappears with the cold sociometry. With it, sociometric interventions appear as the opposite of "freedom of choice". This happens at the same time as criticism of sociometry increases: "institutions using the sociometric test in earnest have often been suspected of using it as a backhanded way of introducing segregation" (J. D. Moreno 2014, p. 130). 


\section{Entrance to an analysis of a living sociometry}

In the following, I will project a way of using sociometry today as a means to promote sociometry's potential as democratic idea and cultural practice. It is based on theatre practice and is a continuation of the Stegreiftheater form. I will do this by the help of an in-depth interview with a pioneer in sociometric work, Monica Zuretti.

Monica Zuretti is a lecturer at Facultad de Psicología, Universidad de Buenos Aires. She was trained in sociometry by J. L. Moreno and Zerka Moreno and has used this expertise in her theatre practice for more than 45 years. She is a pioneer that has taught around the world both as lecturer and practitioner. Zuretti has extensive experience with voluntary groups in civil society and it was in this respect I met her in Lucca, Italy, where I carried out the in-depth interview in October 2015. The interview was recorded and has been transcribed. In addition to the transcribed text, I have handwritten notes made before and during the interview. The interview is based on an interview guide and "member checking" has been carried out twice. The transcribed interview has been translated into Spanish and sent to the researcher participant, as is the analysis presented in the article. The transcribed text and the notes constitute the main material for my analysis. In the analysis of the material, the guiding principle has been the relationship sociometry's early idea as democratic practice and how the theatre tool may contribute to transformation of social reality. Based on the ambition to revitalize sociometry as a phenomenon, I will continue to shed light on it from a democratic theatre practice.

\section{Understanding of sociometry}

In her understanding of sociometry, Monica Zuretti refers to Who Shall Survive?, which describes sociometry as a fundamental language: "A basic language" (J. L. Moreno 1953, p. 31). Where people meet, there is sociometry. It exists as a basic language, a language that continually shifts and appears through human choices. Sociometry is, she says. It is living in human encounters. People choose in encountering each other. Encounters and contacts in groups and societies constitute structures between people. The structures are there whether they are the object of sociometric investigation or not. We can, then, talk about living sociometry as something that is, as something that shifts and that is not static. As opposed to a cold sociometry that is characterized by a written sociogram and where the choices are marked by numerical rankings, a living sociometry is characterized by mobility. People may choose again, they may make new choices where the old choices are no longer helpful, including in human relations.

It is such reasoning Monica Zuretti presents when she talks about her own understanding and use in the practice of sociometry. She defines sociometry as relations

\footnotetext{
6 "Member check" is a qualitative method that gives the researcher the opportunity to make sure that the text excerpts from interviews and interpretations in the analysis is in accordance with the researcher participant's views (Carlson 2010).
} 
between humans in groups. Her departure point is sociometry as something that is when she works with groups, new and old, open and closed alike. To her, sociometry is something alive and movable; therefore she uses the expression living sociometry about her work. It is possible to observe and see sociometry. Asked what she means when she says see sociometry, her answer is that when people get together, groups arise. Some know each other, some are new, groups and dyads arise. Some remain standing on the outside of it all. ${ }^{7}$ Different kinds of liveliness are also expressed in the formation of groups; laughter, gesticulations, conversation etc. The formation of group structures is possible to observe; they can be seen. Sociometric structures that constitute isolated individuals and stars appear. Zuretti rarely uses sociograms in her work because it is her experience that it is possible to work directly with the sociometric structures in groups. Sociograms tend to lock perceptions and positions. Numerical rankings in the form of choices, for instance concerning who wants to sit next to who at the table, easily become static. They often lead to locking. On the other hand, it is obvious that we choose based on what is expedient and helpful in varying situations.

\section{Use forms in practice}

When Monica Zuretti describes how she puts her understanding of sociometry to use in practice, she uses the above mentioned as a starting point. There exists an observable sociometric structure. It is conscious. What is not so conscious at group level, are the varying perceptions of the group members. Perceptions, people's varying opinions, sensations, views and notions, constitute a co-conscious part of groups' lives. Our experience and way of thinking, notions and behavior are woven into the way we act, she says while referring to Who Shall Survive?: "cognition, perception, behavior and action are finely interwoven and cannot be finely separated." (J. L. Moreno 1953, p. 78). Through the use of the theatre medium, this can be communicated. The theatre medium is a key concern in a living sociometry. A living sociometry arises in the fracture surface between a firm, conscious group structure and a structure which is open to the perceptions of the members. There is a constant conflict here, a conflict between the firm and the many-faceted. When we open to the perceptions in a group, we also open to diversity. In a healthy democracy, the different voices of the individuals must be allowed expression and with this, we also open up to a diversity of lived life. A living sociometry is to work with this.

Various enactments of group voices in the form of small theatre productions, image theatre and sculptural works often bring forward the different perceptions of the group. Through role work and fictitious role presentations, one may see matters of attitude that bring a group together around some common experiences. The perceptions need to have enough energy in them to bring the group together in a new way. Sensory experiences that touch the group as a whole become important.

\footnotetext{
7 Sociometry starts with an understanding of encounter (Kristoffersen 2013).
} 
In Buenos Aires I had a learning group once that consisted of a German man and the rest Argentinians. The topic we worked with was sociometry. We were in an early phase of the group formation when I asked the group what expectations they had towards our work. To find an answer, they had to cooperate. They gathered in small groups and spontaneous theatre productions arose, showing their varying expectations. The German man had expectations related to experiences of freedom. In his group a scene was staged of being pulled by a toboggan through the snow on a winter's day in his childhood Germany. The scene was played several times and the aesthetic presentation of freedom was shown from different positions. To be able to see the scene, he chose an Argentinian woman to play himself being towed through the snow on a toboggan. To the Argentinian woman, this scene evoked another memory. The toboggan for her became a memory of her Jewish grandfather being pulled by a toboggan through Poland to escape the Germans during the war. The toboggan represented the opposite of freedom to her. They came from two different cultures, they met in Argentina and different perceptions linked to a toboggan became a cultural meeting that went several generations back in time. The woman's story about her Jewish grandfather and the German man's perception of national identity was the further subject of scenic productions. By help of the productions, the sociometric structures in the group changed. Included in this change was the fact that the Argentinian woman and the German man became friends.

Humans carry experiences and ways of thinking, perceptions and behavior woven into ways of acting; often they are co-conscious. Here, perceptions linked to a toboggan become important for the sociometric structure of the group, Zuretti says. It becomes a symbol that can be communicated through a theatrical language. To a sociometric knowledge belongs the fact that there exists both something visible and something invisible when group relations and group structures arise. The invisible structures are linked to man's varying perceptions and imaginations and in a living sociometry this has to be given place, in this is included the use of the theatre medium, Zuretti concludes.

\section{Conclusion}

The article has had as its starting point an early sociometric idea and practice as it is presented in the 1930s. Through literature and interview I have looked for traces of continuity and renewal as related to today's practice. To make clear a distinction between cold sociometry and living sociometry, a distinction that is expressed through different knowledge and culture views, both in theory and practice, is central here. The early sociometry that has been described is based on a view on knowledge that presupposes theatre practice and the voice of the self in society and school. This has disappeared from sight through unilateral use of the sociogram as a test and diagnostic method from the 1960 s up till today. In working with a living sociometry, one first has to see that sociometry is in relations and that it has to do with being able 
to "read" an interpersonal diversity and contribute to mutual esteem in groups. To this end, the theatre tool and the individual's participating voice are fundamental.

Open Access This article is distributed under the terms of the Creative Commons Attribution 4.0 International License (http://creativecommons.org/licenses/by/4.0/), which permits unrestricted use, distribution, and reproduction in any medium, provided you give appropriate credit to the original author(s) and the source, provide a link to the Creative Commons license, and indicate if changes were made.

\section{References}

Carlson, J. A. (2010). Avoiding traps in member checking. The Qualitative Report, 15(5), 1102-1113.

Dewey, J. (1961). Democracy and education. An introduction to the philosophy of education. New York: Macmillian.

Dewey, J., \& Dewey, E. (2008). Schools of to-morrow. New York: Dover Publications.

Fox, J. (Ed.). (1987). The essential Moreno. Writings on psychodrama, group method, and spontaneity by J.L. Moreno, M.D. New York: Springer.

Hellevik, O. (1977). Forskningsmetode i sosiologi og statsvitenskap. Oslo: Universitetsforlaget.

Kristoffersen, B. (2013). Isolasjon er lidelse. Drama. Nordisk dramapedagogisk tidsskrift. No. 03/2013. (pp. 20-27).

Løkken, G., \& Frode, S. (2013). Observasjon og intervju i barnehagen. Oslo: Universitetsforlaget. Original edition 1995

Marineau, R.F. (1989). Jacob Levy Moreno, 1889-1974: father of psychodrama, sociometry and group psychotherapy. London: Routledge.

Marineau, R.F., \& Moreau, M.-L. (2003). Moreno movies. Spontaneity training and role re-training (around 1933)—introduction to psychodrama (around 1942). San Francisco: Psychotherapy.net. Disc. 1

Moreno, J.D. (2014). Impromptu man. J. L. Moreno and the origins of psychodrama, encounter culture, and the social network. New York: Bellevue Literary Press.

Moreno, J. L. (1953). Who shall survive? Foundations of sociometry, group psychotherapy and sociodrama. New York: Beacon House.

Moreno, Z. (2012). To dream again. A memoir. New York: Mental Health Resources.

Moreno, J. L. (1934). Who shall survive? A new approach to the problem of human interrelations. Washington, D.C: Nervous and Mental Disease Publishing Co.

Moreno, J. L. (1983). The theatre of spontaneity. Pennsylvania: Beacon House. Original version in German in 1923

Rasmussen, B., \& Børge, K. (2011). Handling og forestilling. Forestilling om handling. Jacob Levy Morenos teaterekspresjonisme og sosiatri. Trondheim: Tapir Forlag.

Rasmussen, B., \& Børge, K. (2014). Mye på spill. Teater som danningspraksis i skolen. Bergen: Fagbokforlaget.

Sletta, O. (1983). Sosiale bytteforhold ved samspill i skoleklasser. Trondheim: UNIR, Pedagogisk institutt.

\section{Further reading}

Dewey, J. (1980). Art as experience. New York: Perigee Books. 


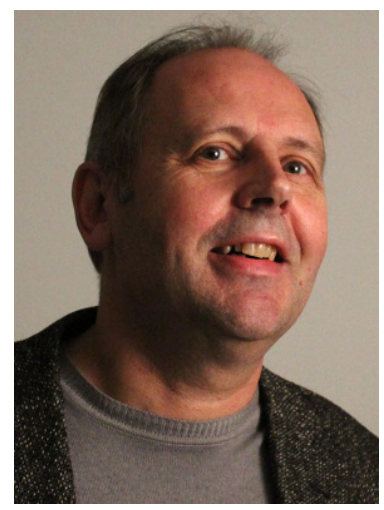

Børge Kristoffersen (1955) is professor at Queen Maud University College, in Trondheim, Norway and Director of Sociopsychodrama. 